\title{
Razones y sinrazones que demoran la desjudicialización del divorcio en Argentina*
} Reasons and lack of reasons that delay
the dejudicialization of divorce in Argentina

\author{
Martín Miguel Culaciati**
}

\begin{abstract}
RESUMEN
Es nuestra intención contribuir al debate actual que presenta la nueva fisonomía del divorcio, y las modificaciones que éste debería encarar para estar en total consonancia con la doctrina internacional de los derechos humanos. El ejercicio de un derecho no conlleva necesariamente su judicialización. Así, la desjudicialización del divorcio consensual constituye el paso siguiente en su evolución, que ya no debe ser visto como un proceso, sino como la exteriorización de la finalización de la relación afectiva. Esta denuncia alitigiosa debe ser externada de la sede judicial y escindida de las cuestiones relativas a la ruptura marital pues, además, ello supondría la reducción del conflicto familiar al que los hijos se ven expuestos; reduciendo los costos económicos, psicológicos y emocionales a los estrictamente ocasionados por el quiebre afectivo, sin añadir los propios del proceso. Ello, finalmente, nos permite como beneficios adicionales la descongestión del sistema judicial, la racionalización y la redistribución de los recursos humanos.
\end{abstract}

PALABRAS CLAVE: Divorcio incausado, affectio maritalis, desjudicialización, divorcio por mutuo acuerdo, sede notarial.

\begin{abstract}
It is our intention is to contribute to the current debate that presents the new face of divorce, and the changes that it should address to be in conformity with the international doctrine of human rights. The exercise of a right does not necessarily entail its prosecution. Therefore the dejudicialization of consensual divorce is the next step in the evolution, which should no longer be seen as a process, but as the externalization of the conclusion of the affective relationship. This complaint litigation must be externalized from the courts and separated from issues relating to the marital breakdown because, in addition, it would imply a reduction of family conflict to which children are exposed; reducing the economic, psychological and emotional costs to those strictly caused by the affective breakdown, without adding to the process. This, finally, allows us as an additional benefit, of decongestion of the judicial system, and the redeployment of human resources.
\end{abstract}

KEY WORDS: No fault divorce, conjugal affection, dejudicialization, divorce by mutual agreement, notary office.

\footnotetext{
* Recibido: 9 de marzo de 2015. Aprobado: 27 de abril de 2015.

** Consejero de la Magistratura del Poder Judicial de la República Argentina. (mculaciati@gmail.com)
} 


\section{SUMARIO}

1. Breve introducción

2. La nueva fisonomía del divorcio

3. El próximo paso: la desjudicialización del divorcio

4. Razones que propician la vía extrajudicial

5. Las piedras en el camino de la desjudicialización

6. Objeciones juridicas a la desjudicialización

7. La sede notarial

8. Colofón

"Resulta más fácil sustituir en las usinas material envejecido por máquinas nuevas que sustituir un aparataje jurídico tradicional por el nuevo orden jurídico". GeORges Ripert

\section{Breve introducción}

En el último siglo se produjeron grandes cambios socioculturales que impactaron el derecho de familia y permitieron un cambio de paradigma, donde el punto de partida solía ser la "institución familiar", para pasar a analizar el derecho de la persona "a vivir en familia". Entonces, ¿qué ocurre con el divorcio en este contexto de cambios? Ciertamente, no puede tener la misma fisionomía de antaño, ${ }^{1}$ y a ello apunta este aporte: a reinterpretar el divorcio a la luz de aquellos cambios.

Ha sido largo el camino que hemos transitado, hasta que el legislador entendió que el régimen causado de divorcio había prescrito. Creemos que la desjudicialización de su trámite es el siguiente paso en su lenta pero inexorable evolución y adecuación a la idiosincrasia actual de nuestras sociedades.

En efecto, cada vez más países regulan regímenes jurídicos mixtos de divorcio que, cuando no hay conflicto, permiten a los cónyuges resolver su vínculo sin judicializar su trámite. Sin embargo, esta opción no ha logrado afıncarse aún en la Argentina.

\footnotetext{
1 Encarna Roca sostuvo que "si hay que preservar en todo caso los derechos individuales de los miembros de la familia, la garantía de los derechos fundamentales a la libertad y a la intimidad implica el reconocimiento de un sistema de divorcio que tenga como eje la no indagación sobre las causas que lo provocan". Roca Trias, Encarna. Familia y cambio social (de la "casa" a la persona), Civitas, Madrid, 1999, p. 166.
} 
En este breve aporte, indagaremos en torno a las razones y sinrazones que, a nuestro juicio, impiden de momento la desjudicialización del divorcio en nuestro país.

\section{La nueva fisonomía del divorcio}

Si nos basamos en que lo principal es el ser humano y sus necesidades, y que el derecho es un medio para el logro de fines más elevados que la vigencia de la ley misma, es fácil advertir que, desde el momento en que la institución matrimonial pasó a ser más importante que el afecto entre las personas que la componen, la óptica debe ser modificada. En caso contrario, los esposos terminan siendo rehenes de una institución que contraría sus proyectos biográficos. Eduardo Galeano nos recuerda: "Estamos en plena cultura del envase. El contrato de matrimonio importa más que el amor, el funeral más que el muerto, la ropa más que el cuerpo y la misa más que Dios".

El matrimonio se apoya en la relación afectiva de dos personas, cuya intención "inicial" es asegurar ese vínculo; a pesar de los argumentos metajurídicos que denostaron durante siglos aquello que el derecho romano denominó affectio maritalis. En esa línea de pensamiento, cabe destacar la apertura al afecto como concepto jurídico y su desaparición como causal de divorcio.

Ahora bien, el nuevo Código Civil y Comercial argentino nos propone la revalorización y juridización del afecto o, en palabras de Kemelmajer de Carlucci "la apertura al 'afecto' como concepto jurídico"; pues hasta su sanción, la afectividad era una característica implícita de la relación matrimonial, pero hasta ahora era jurídicamente irrelevante. En la mente del legislador, desaparecido el afecto entre los cónyuges, se desvanece la causa de la relación matrimonial. De allí se desprende la relevancia del afecto para la perdurabilidad del matrimonio, y su desaparición como substrato volitivo para peticionar el divorcio. Justamente, el régimen de divorcio sin expresión de causa es el que mejor responde a la manda constitucional de autonomía y libertad.

El profesor Lasarte Álvarez ${ }^{2}$ sostuvo que cuando la crisis surge "lo mejor es certificar la defunción del matrimonio sin ambages y permitir que, con la mayor celeridad posible, los cónyuges procuren rehacer su vida el uno lejos del otro", pues, naturalmente, si se les reconoció madurez suficiente para comprometerse matrimonialmente, ¿cómo se les va a negar capacidad y serenidad suficiente para poner fin a la situación matrimonial?

\footnotetext{
${ }^{2}$ Lasarte Álvarez, Pedro C. "Merecido adiós al sistema causalista en las crisis matrimoniales", en Actualidad Jurídica
} Aranzadi, No. 655, 2005. 
Situados paralelamente, entonces, la affectio maritalis, y su ausencia como fundamento último del divorcio, se iguala a la libertad para casarse con la libertad para divorciarse, cuando en ambos casos hay consenso.

García Cantero, ${ }^{3}$ crítico de la reforma española de 1981, sostuvo: "no cabe olvidar que desde siempre ha existido una estrecha relación entre el divorcio y el proceso de divorcio, y que los caracteres de éste último revelan los rasgos fundamentales del divorcio mismo". En ese sentido, si el divorcio ha cambiado sustancialmente (para justificarse en la desaffectio maritalis), convirtiéndose en el contrarius actus del matrimonio (fundado, desde siempre, en la affectio maritalis), el cambio en lo procedimental parece inevitable. ${ }^{4}$

Planteamos así una visión distinta en torno al matrimonio y el divorcio, en el entendimiento de que si cambiamos la forma de ver las cosas, las cosas cambian de forma.

A tal efecto, seguimos la línea sustentada por el jurista español Clavería Gonsálvez, ${ }^{5}$ hace ya varios años, acerca de concebir al matrimonio como la unión de dos personas que han exteriorizado, de la forma prevista en la ley, su relación afectiva. "Existiría, por tanto, matrimonio por y tras la comunicación formal al Registro Civil de dicho proyecto de convivencia. En este contexto, la figura del divorcio carece de sentido, bastando, en línea de principio, la mera comunicación (a modo de "denuncia") al mencionado Registro, por parte de uno de los cónyuges, para que legalmente se repute extinguida la relación matrimonial".

Así, el proceso de divorcio (que debe escindirse finalmente de las cuestiones relativas a la ruptura del vínculo marital) carece de sentido.

Isabel Tapia Fernández ${ }^{6}$ reflexiona en torno a la necesidad de un proceso de divorcio; su razonamiento es sumamente interesante. La autora, refiriéndose a la experiencia española, consideró que "no se justifica una regulación especial, cuando la única pretensión de tutela es el puro estado civil de las personas, sin repercusiones con relación a los menores”.

¿Para qué un proceso en el que la decisión le viene impuesta al Juez en atención a lo pedido por el actor? Entiendo que [...] la falta de adecuación de la pretensión de divorcio con el sistema procesal arbitrado

\footnotetext{
${ }^{3}$ Garcia Cantero, Gabriel. Comentarios al Código Civil, Edersa, Madrid, 1982.

${ }^{4}$ Cerdelra Bravo de Mansilla, Guillermo. Matrimonio y Constitución (presente y posible futuro), Reus, Madrid, 2013, p. 305. ${ }^{5}$ Claveria Gonsálbez, Luis H. "Hacia una nueva concepción del matrimonio", en La Ley. Revista jurídica española de doctrina, jurisprudencia y bibliografía, 1983, p. 1298.

${ }^{6}$ TAPiA Fernández, ISABel. "El nuevo proceso de divorcio tras la promulgación de la Ley 15/2005, de 8 de julio: ¿necesidad de un proceso especial?, ¿necesidad de un proceso?", en Aranzadi Civil, No. 1, 2006, p. 2262.
} 
para su exigencia es patente. Y no sólo porque la nueva regulación no justifique la existencia de un procedimiento especial [...]; es que ni siquiera justifica la existencia de un proceso jurisdiccional. Pienso que el trámite de un expediente de jurisdicción voluntaria o, incluso, la comparecencia ante un fedatario público podría ser suficiente para satisfacer la pretensión de divorcio.

El automatismo del divorcio parecería no justificar la existencia de un proceso. Si la desaparición del afecto es la única razón del divorcio, la cual los cónyuges por voluntad denuncian para legalizar el quiebre marital, éste ya no requerirá un proceso judicial, ni siquiera requerirá un proceso. Esta instantaneidad $\mathrm{d}^{7}$ hace que el divorcio no pueda ser concebido como un proceso transitable sino como la legalización del quiebre marital acaecido; en no pocas ocasiones, mucho antes que su arribo al órgano estatal.

\section{El próximo paso: la desjudicialización del divorcio}

A esta altura del análisis, ha quedado claro que la garantía de los derechos a la libertad y a la intimidad conlleva la restricción en la indagación de las causas que provocan el divorcio. Sin embargo, la ley aún deposita en los jueces la confianza para poder -antes, reconciliar, ahora- "resolver" el problema que le traen los cónyuges. Este problema no es ni más ni menos que la pérdida del vínculo afectivo subyacente. ¿El divorcio es una cuestión privada o pública? Consideramos que el divorcio es una cuestión privada, amparada por la manda constitucional donde el Estado interviene al sólo efecto de fiscalizar el estado civil de las personas. Hecha esta aclaración, cuadra advertir que, en un divorcio consensual, ante la ausencia de conflicto, el profesional interviniente no debe dirimir quién tiene razón, sino si se cumplen los requerimientos legalmente exigibles.

Cualquiera sea la sede, la desjudicialización constituye el paso siguiente en este camino, el cual propone la nueva fisonomía del divorcio y, en definitiva, contribuye a facilitarle la vida a la gente. No debemos ver en ella un retroceso o pérdida de derechos; por el contrario, implica una ampliación de éstos. En rigor, la política de desjudicialización en materias que ya no representan un conflicto en sí mismo, contribuye a la mayor eficacia en el goce y ejercicio de los derechos.

\footnotetext{
7 Véase también Navarro Viñuales, José Maria. "La tendencia desjudicializadora en el nuevo Derecho de Familia", en Navarro Viñuales, José M. (Dir.), El nuevo Derecho de Familia: Modificaciones legislativas y tendencias doctrinales, Civitas, Cizur Menor, 2006, pp. 286-290.
} 
La desjudicialización constituye, en esta línea de pensamiento, el paso siguiente en la evolución del divorcio, el cual debemos observar como una denuncia o exteriorización ante el Estado de la finalización de la relación afectiva que sustentaba el matrimonio. Es el Estado el mayor interesado en que sus registros se condigan con la realidad.

Esta denuncia alitigiosa, que sólo exige la constatación de la voluntad y ciertos requisitos, debe ser externada de la sede judicial y escindida de las cuestiones relativas a la ruptura marital. Además, ello supondría la reducción del conflicto familiar al que los hijos se ven expuestos, así, como los costos económicos, psicológicos y emocionales a los estrictamente ocasionados por el quiebre afectivo, sin añadir los propios del proceso judicial. Esto, por propiedad transitiva, contribuye a cimentar la relación en la etapa post-divorcio.

Ello, finalmente, nos permite un beneficio adicional que está dado por la descongestión del sistema judicial, la racionalización y redistribución de recursos humanos: se evita la intromisión de la judicatura en la privacidad familiar.

Cada vez más países regulan regímenes jurídicos mixtos de divorcio, los cuales, cuando no hay conflicto, permiten a los cónyuges resolver su vínculo sin judicializar su trámite.

Embarcados en la desjudicialización, los procedimientos regulados y los funcionarios, ante quienes se sustancian, divergen. Ello conlleva importantes diferencias respecto a la naturaleza del procedimiento, el funcionario autorizante y los requerimientos exigibles para acceder a la sede extrajudicial.

Como se ha concluido en un importante evento académico: "consideramos que cada familia y sus integrantes tienen derecho a la garantía de efectividad de las políticas de sostén de sus reclamos y conflictos sin necesidad de judicializar sus peticiones". ${ }^{8}$ En otras palabras, el ejercicio de un derecho no conlleva necesariamente su judicialización.

Son muchos los aspectos que implica la desjudicialización del divorcio y que podrían ser objeto de un examen detenido. No obstante, en un afán sintetizador, seleccionaremos para su consideración aquéllos que generan mayor controversia.

\subsection{La intervención judicial y la inercia de la consolidación cultural}

El divorcio trasciende el mero acuerdo de los cónyuges, aunque únicamente se sustancien intereses privados, pues su efectividad depende de la legalización de

\footnotetext{
${ }^{8}$ EI XVII Congreso Internacional de Derecho Familiar, reunido en Mar del Plata entre el 22 y el 26 de octubre de 2012, emitió la "Declaración universal de los Derechos humanos de las familias". Su texto puede verse en Derecho de Familia, 2013, p. 7; Loyarte, Dolores, Declaración de Mar de la Plata: Declaración Universal de los Derechos Humanos de las familias, cita: AP/DOC/367/2013. Puede verse en particular el artículo 14.
} 
la ruptura afectiva. Allí aparece el ingrediente público. De ahí, que la participación de un funcionario público se encuentre plenamente justificada.

Ahora bien, ¿ése funcionario debe necesariamente ser un juez? Esta pregunta sobrevuela todo nuestro aporte aunque consideramos que la respuesta negativa se impone. Prestigiosos autores que ya han transitado este largo, pero inexorable camino hacia la desjudicialización, advierten que un proceso de divorcio consensual responde a los esquemas propios de un procedimiento de jurisdicción voluntaria, con ausencia del principio contradictorio. Ello favorece la atribución de la competencia a funcionarios no judiciales.

Desjudicializar instituciones familiares no supone, de modo alguno, erosionar las normas imperativas del derecho familiar; 9 por el contrario, la judicialización del divorcio presume un viso de litigiosidad y conflictividad que no siempre existe. ${ }^{10} \mathrm{Si}$ bien al Estado y la sociedad les interesa conservar la estabilidad de las familias [vale recordar, no debemos confundir con matrimonios], no es menos cierto que le son indiferentes los aspectos íntimos del amor $\mathrm{y}$, por tanto, no puede -ni debe- regularlos jurídicamente.

Ahora bien, la desjudicialización propuesta no se apoya exclusivamente en la falta de conflicto ínsito en el divorcio consensual. Existen distintas circunstancias históricas que llevaron a atribuir la competencia originariamente a los jueces y, mediante un largo período de consolidación cultural, hicieron que aquella permaneciera inalterada.

\section{2 ¿Por qué el divorcio es judicial? Razones y mitos}

Cuando comenzamos a indagar, nos encontramos con una apelación al statu quo, es decir, el divorcio siempre fue así: judicial. Es cierto, incluso tautológico, pero esta circunstancia, impuesta mediante un largo período de consolidación cultural, no comporta per se suficiente justificación para perpetuar, sin mayor análisis, la necesidad de judicializar el ejercicio de un derecho. Por ello, aquella afirmación -que prima facie aparece incuestionable- debe ser revisada.

¿Cuáles son las posibles razones que llevaron a atribuir originariamente la competencia a los jueces? No obstante el limitado alcance de la noción de divorcio, desde los albores de la consolidación de las naciones latinoamericanas, el análisis de la ruptura conyugal estuvo a cargo de un juez porque era considerado un conflicto que debía evitarse, o por lo menos restringirse

\footnotetext{
${ }^{9}$ Pérez Gallardo, Leonardo B., "Un fantasma recorre Latinoamérica en los albores de este siglo: el divorcio por mutuo acuerdo en sede notarial", en Anuario de la Facultad de Derecho, No. 27, 2009, p. 333.

${ }^{10}$ Carrión Garcia de Parada, Pedro. "Aspectos jurídicos y fiscales del divorcio amistoso", en Revista Jurídica del Notariado, No. 34, Consejo General del Notariado, Madrid, 2000, p. 70.
} 
cuantitativamente. Sólo el recto criterio de un juez podía evaluar que las causas alegadas fueran tan graves como para terminar con una familia legítima y sancionar al culpable. En suma, la noción de divorcio sanción, proveniente del derecho canónico, ${ }^{11}$ conllevaba la existencia misma de un litigio y, en todo litigio, interviene un juez.

Inclusive, "la judicialización del divorcio obedece más a razones históricas, fruto de una época en que jurisdicción y administración estaban encomendadas a jueces, que a la propia esencia de esta institución". ${ }^{12}$ En Argentina, los juzgados civiles y los jueces de paz se establecieron tempranamente en todo el territorio nacional.

Esta fue la realidad vigente al llevarse a cabo los debates previos a la sanción de la ley de matrimonio civil. El divorcio era una excepción, un litigio y, fundamentalmente, una sanción al culpable de un hecho ilícito, y como tal, sólo podía ser dispuesta por un juez.

Ahora bien, ¿estas razones conservan la debida actualidad para fundamentar esta atribución exclusiva y excluyente del juez? Creemos que la respuesta negativa se impone. Las razones esgrimidas para justificar históricamente la competencia judicial han perdido vigencia. ${ }^{13}$ Sucede que si logramos entender que el divorcio consensual no es un litigio, sino una posible solución a los problemas -a veces, inevitables- de un matrimonio, se colige que la actuación de un juez deviene innecesaria.

En definitiva, el hecho de que el divorcio siempre haya sido judicial no constituye una razón en sí misma. Si así fuera, nos limitaríamos a rebatirla con el conocido villancico español: "las cosas son como son hasta que dejan de serlo”. Por ello, exploramos las razones coyunturales que llevaron a

\footnotetext{
${ }^{11}$ Cuadra recordar que el Código Civil redactado por Vélez Sársfield, vigente desde el año 1871, establecía una única modalidad para contraer matrimonio: el matrimonio religioso. Por ello, las causales de divorcio no vincular (o en términos canónicos, separación de cuerpos quoad torum y habitatione) entre personas casadas ante la Iglesia católica eran competencia exclusiva de los tribunales eclesiásticos. De este modo, impuso una regulación que significara la continuidad del derecho patrio el cual, a su vez, provenía de la legislación colonial en la que se fundian Estado y religión.

12 Pérez Gallardo, Leonardo B. "El divorcio por mutuo acuerdo en el derecho cubano: Mitos y tabúes", en Revista de derecho privado, Edersa, 2007, pp. 65-103.

${ }^{13}$ En la Exposición de Motivos del Anteproyecto de Ley de Jurisdicción voluntaria español se dice: "la consideración de los recursos organizativos personales y medios materiales puestos en la actualidad a su disposición, así como del elevado grado de modernización y especialización que alcanza hoy la Administración pública, profesionalizada y regida por los principios de objetividad, eficacia e interdicción de la arbitrariedad, y sujeta a la Ley y al Derecho por mandato constitucional, justifican igualmente la apuesta por la desjudicialización de ciertas materias que hasta ahora eran atribuidas a jueces y magistrados. Esto último pone de relieve que hoy han perdido vigencia algunas de las razones que justificaron históricamente la atribución de la jurisdicción voluntaria, en régimen de exclusividad, a los jueces; pues, junto a ellos, las sociedades avanzadas cuentan en la actualidad con otras opciones viables para la efectividad de los derechos privados, cuando para ello se requiera la intervención o mediación de órganos públicos".
} 
atribuirle la competencia a la judicatura y perduraron, gracias a un proceso de consolidación social. Hemos verificado que aquellos motivos originarios para la actuación exclusiva del juez no conservan una actualidad que permita su indubitable continuidad. La carencia de esa perennidad que se le pretende atribuir nos anima a confrontar esta realidad.

\section{Razones que propician la vía extrajudicial}

No sólo los motivos coyunturales que llevaron a atribuir la competencia a los jueces han perdido vigencia; sino que la misma lógica del divorcio sin expresión de causa nos lleva a proponer la coincidencia entre la ruptura conyugal y el procedimiento para llevarla a cabo.

Así, la desjudicialización contribuiría a que el trámite no genere más dolor a los hijos que la ruptura de la relación genera en el plano afectivo o social. Además, la vía extrajudicial supera la problemática de la dificultad de acceso a la justicia y la demora en la efectiva prestación jurisdiccional. Todo ello evitaría el ámbito propicio para el pleito, reduciría los tiempos del quiebre matrimonial y, a la vez, redundaría en la descongestión del sistema judicial (no por el desahogo en sí mismo, sino por la agilización del servicio de justicia que conllevaría).

En fin, creemos que existen sobradas razones para el cambio.

\section{1 ¿Un tercero superior e imparcial que resuelva conflictos ajenos?}

La gestión de los conflictos interpersonales no requiere necesariamente de un tercero superior que les imponga "su solución" a las partes, pues existen medios alternativos o complementarios para la resolución de conflictos. Si ello es así frente al litigio, más aún cuando éste, lisa y llanamente, no existe.

¿Por qué se requeriría, estando ambos cónyuges de acuerdo en la ruptura, que un tercero superior -juez- interceda y decrete su divorcio? Salvo el resguardo de los derechos de los sujetos menores de edad o incapaces, mediante la intervención del defensor de menores, ¿por qué un tercero debería entrometerse en lo acordado por dos personas adultas? Acudiendo a las reflexiones de Rondina, ${ }^{14}$ "¿De qué mágico poder se cree dotado a los jueces a fin de hacer mutar las decisiones adultas y libres de los cónyuges?”.

\footnotetext{
${ }^{14}$ Rondina expuso: "ninguna relación legal posee la fuerza necesaria para postergar el hastío o el encuentro, impedir la renovada elección o el desengaño. Si nadie escapa al albur de que al año de matrimonio asuma el gobierno conyugal un frío otoñal devastador, cuál es la razón que justifica la existencia de una norma que prorrogue el realismo". Tribunal de Familia No. 2 La Plata, 26/08/2010, "O. S. T. v. D. J. E. s. divorcio vincular contradictorio".
} 
Los protagonistas, tanto de la unión como de la ruptura conyugal, son los esposos y no requieren que un tercero imparcial medie entre ellos. Cuando dos adultos tomaron la decisión de separarse, lo que menos necesitan es alguien que se los impida o intente reconciliarlos en nombre del Estado, ${ }^{15}$ sino alguien que se limite a registrar que el destino conjunto que alguna vez imaginaron, ya no existe.

Cuando los esposos acuden a tribunales, ya han atravesado por un largo proceso emocional. En muchas ocasiones se encuentran separados y han continuado su proyecto biográfico, incluso con otra pareja. Los cónyuges sólo se limitan a exteriorizar una decisión ya tomada y no necesitan la supervisión y consejos de alguien que - no obstante la magistratura con la que se encuentre investido- quizás haya atravesado o esté atravesando la misma situación personal. Creemos que el juez ya no resulta necesario en el divorcio, salvo que se le imponga la tarea de ser un mero espectador.

\subsection{Propiciar el diálogo entre los cónyuges}

Si los protagonistas son los cónyuges -y no el judicante-, la ley debe reducir las posibles consecuencias nocivas derivadas del divorcio para todos los miembros de la familia, fomentando la comunicación y el diálogo entre ellos.

Darle mayor protagonismo a los cónyuges en sede de divorcio supondría que la solución sea de su propio agrado, se simplifique el proceso, se obtenga el divorcio con celeridad, se reduzca el costo económico, psicológico y social, se logre mayor predisposición al cumplimiento futuro de las convenciones obtenidas y, a su vez, los ex cónyuges se vean imbuidos, una vez obtenido el divorcio, en mantener una estable y armónica relación entre ellos y con sus hijos. ${ }^{16}$

Retrospectivamente, nos preguntamos: ¿cómo era posible alcanzar ese objetivo permitiendo a los esposos probar malas conductas en un proceso judicial ante un tercero que jamás han visto y con quien no poseen una relación de confianza? Por el contrario, proponer otras sedes distintas no implica en modo alguno resignar la función judicial como órgano encargado de imponer la ley en casos donde no resulta posible la solución autónoma. Se trata, en definitiva, de que las partes recuperen su rol protagónico en las decisiones que afectan su propia vida y las de sus hijos. ${ }^{17}$

\footnotetext{
${ }^{15}$ Rodrigues, Silvio. O Divórcio e a Lei que o Regulamenta, Saraiva, São Paulo, 1978, p. 73.

"Si dos personas capaces, obedeciendo a las reglas legales, desean dar por terminada la sociedad conyugal de la cual participan, si tales personas, actuando libre y conscientemente, manifiestan su voluntad en tal sentido, es exorbitante la actitud del poder público, pretendiendo dificultarles el paso".

${ }^{16}$ Carrión Garcia de Parada, Pedro. "Aspectos jurídicos...", op. cit., p. 71.

${ }^{17}$ Mattera, Marta del Rosario. "El juez frente al divorcio: respeto por la autonomía y privacidad de los cónyuges", en Derecho de Familia, No. 16, 2000, p. 83.
} 
Por otro lado, extraer el proceso de divorcio de la sede judicial contribuye a desterrar esa idea de "querer mostrarle al juez lo que un cónyuge le hizo al otro" y que una sentencia lo declare culpable. La figura del juez representa el poder y resuelve quién es el "ganador" y quién el "perdedor". Esta lógica desaparecería si el divorcio fuera decretado por un funcionario público y no por un juez.

\subsection{La descongestión judicial}

La judicialización de una cuestión alitigiosa produce un efectivo dispendio de tiempo útil, medido en sorteos, demoras, esperas y desplazamiento de los cónyuges desde sus domicilios hasta la sede judicial. Así, dentro del marco de las distintas actuaciones que lleva a cabo la judicatura, se despliegan un cúmulo de funciones aglutinadas bajo el nombre de jurisdicción voluntaria, que ejercen los jueces con el objeto de integrar, constituir o acordar eficacia a ciertos estados o relaciones jurídicas privadas. Estos actos están contenidos en obrados de naturaleza alitigiosa; por tanto, la función resultaría ajena al normal cometido de los jueces, cuyo objetivo es la resolución de conflictos interpersonales.

Cuadra advertir que la sustanciación de los juicios de divorcio le impone a los juzgados de familia una sobrecarga de tareas con la consecuente distracción de recursos humanos y materiales en cuestiones alitigiosas. En ese sentido, se dijo:

es necesario descargar a los jueces aquellas competencias que le han sido atribuidas, por razones de mera tradición, de simple división del trabajo, de oportunidad no justificable en el momento actual o de mero contenido administrativo [...]. Se trataría no tanto de evitar el colapso de la justicia contenciosa, sino de sistematizar y redistribuir competencias en materias de jurisdicción, en aras de la racionalización del sistema. ${ }^{18}$

Con suma claridad, la Resolución 35 del 24 de abril del 2007 que reglamenta la aplicación de la ley 11.411/2007 del 4 de enero, la cual instaura el divorcio notarial en Brasil afirma: "A finalidade da referida ley foi tornar mais ágeis e menos onerosos os atos que se refere e, ao mesmo tempo, descongestionar o Poder Judiciário". La doctrina ${ }^{19}$ sostuvo que la ley constituía "un gran avance

\footnotetext{
${ }^{18}$ Fernández de Bujàn, Antonio. La jurisdicción voluntaria, Cívitas, Madrid, 2001, p. 188.

19 Vainsencher, TÂniA. "El divorcio en el Derecho brasileño", en Acedo Penco, Ángel y Pérez Gallardo, Leonardo B. (coords.), El divorcio en el Derecho Iberoamericano, Temis, Buenos Aires, 2008, pp. 123-145.
} 
en el derecho brasileño, atendiendo a los anhelos de la comunidad jurídica y de la propia sociedad, para la desjudicialización de la extinción de la sociedad conyugal y del matrimonio cuando no hubiese litigio. La tramitación del divorcio en la vía extrajudicial supera la problemática de la dificultad de acceso a la Justicia y la demora en la efectiva prestación jurisdiccional".

En oportunidad de considerar la propuesta de desjudicialización española, ${ }^{20}$ se afirmó:

de la separación de determinados asuntos del ámbito competencial de los jueces y magistrados sólo cabe esperar, pues, beneficios para todos los sujetos implicados en la jurisdicción voluntaria: para el ciudadano, en la medida en que ello debe tener como consecuencia, cuando precise la actuación del Estado para la actuación de un determinado derecho, una mayor efectividad de sus derechos sin pérdida de garantías; para Secretarios judiciales, notarios y registradores de la propiedad y mercantiles, por la nueva dimensión que se les da como servidores públicos, consecuente con su real cualificación técnica y el papel relevante que desempeñan en el tráfico jurídico; $\mathrm{y}$, en último término, para jueces y magistrados, que pueden centrar sus esfuerzos en el cumplimiento de la esencial misión que la Constitución les encomienda, como exclusivos titulares de la potestad jurisdiccional y garantes últimos de los derechos de las personas.

Los jueces tampoco deben ver en el escribano o el registro civil una "competencia desleal" con sus funciones; por el contrario, ambos se complementan. La desjudicialización no supone que el Estado abdica de sus responsabilidades; sólo se trata de posibilitar que la demanda social relativa a la resolución justa de los conflictos pueda llevarse a cabo. No existe ningún sistema judicial que pueda solucionar eficazmente todos los problemas que plantea la conflictiva familiar. Justamente, el equilibrio, noción medular de todo sistema, exige aceptar otros instrumentos que lo descargan y, consecuentemente, ayudan a preservarlo. Creemos que los tribunales no son el ámbito natural para resolver las diferencias conyugales.

Si bien es cierto que la citada descongestión no representa el objetivo primordial que se pretende con la desjudicialización, consideramos que una reducción de aproximadamente $20 \%$ en la cantidad de expedientes ingresados anualmente en los juzgados de familia de la Ciudad de Buenos Aires es

\footnotetext{
${ }^{20}$ Informe cGP sobre Anteproyecto de ley de Jurisdicción Voluntaria 2014, p. 48.
} 
un guarismo para nada despreciable. Máxime si tenemos en cuenta el papel de espectador de lujo que tendrá el juez en los procesos donde los cónyuges coincidan en la petición y en las cuestiones conexas.

Ahora bien, la descongestión bajo análisis no sólo es una descarga de trabajo, sino que representa una racionalización de los recursos humanos y materiales. Cabe traer a colación las palabras de la ley colombiana $n^{\circ}$ 962/2005 la cual, en su artículo $1^{\circ}$ dispone "la presente ley tiene por objeto facilitar las relaciones de los particulares con la Administración Pública”.

\section{Las piedras en el camino de la desjudicialización}

La desjudicialización del divorcio consensual ha generado en los países que ya poseen regímenes mixtos, o en aquellos que se atreven a iniciar los debates que preceden al cambio, toda clase de repercusiones, y entre ellas algunos rechazos. Ahora bien, algunas se limitan a críticas mediáticas o impugnaciones pseudo-gremiales de los colectivos afectados por la potencial modificación legislativa, los cuales se esconden bajo las denuncias de pérdida de derechos de la ciudadanía. Se tratarán a continuación.

Vienen a la memoria las palabras de Adolfo Bioy Casares ${ }^{21}$ quien dijo: "Cree en las ideas y no le importa la gente. -Un filósofo, entonces.- Un fanático”.

A nuestro juicio, si el matrimonio pierde su sentido para los cónyuges y para los hijos, también lo pierde para la sociedad.

\subsection{El factor común de las críticas mediáticas o gremiales}

Un factor común en las impugnaciones es el recurrente temor a la "privatización” del matrimonio y el divorcio. Si bien esta objeción resulta común para ambas sedes extrajudiciales, es mucho más fuerte cuando se promueve la instauración del divorcio en sede notarial.

Veamos a modo de ejemplo los argumentos en los que se apoya esta crítica para luego intentar rebatirlos. En España, los medios de comunicación reaccionaron de igual manera frente al proyecto de ley de jurisdicción voluntaria, al apuntar que "la 'privatización' llega a las bodas: casarse ante notario costará 95 euros” o "Gallardón quiere "privatizar' las bodas y los divorcios pactados. El ministro propone que los ciudadanos paguen a los notarios por una labor que ahora es gratis". ${ }^{22}$

\footnotetext{
${ }^{21}$ Bioy Casares, Adolfo. Una muñeca rusa, RBa ediciones, Madrid, 1994, p. 42.

${ }^{22}$ AguedA, Pedro. "Gallardón quiere 'privatizar' las bodas y los divorcios pactados", 2012, disponible en http://www.
} 
Allí se agrega:

Jueces para la democracia denunció que el anuncio del ministro [...] se inspira en 'una filosofía de mercado' que impone 'desjudicializar para privatizar'. A renglón seguido, se dice que la celebración del matrimonio ante notario no plantea problemas. El matrimonio nace de la voluntad de los contrayentes, que es lo único imprescindible [...]. Nada que objetar a que el consentimiento pueda ser emitido ante un notario, un funcionario público que recibe declaraciones de voluntad, y da fe de ellas.

Pero, ¿acaso el proyecto de ley no implicaba una privatización? El autor no tiene nada que objetar a la celebración del matrimonio ante notario, pero sí en el divorcio ante notario. ¿Será que para el autor no resulta tan preocupante que la celebración del matrimonio sea considerada un acto privado, pero sí que el divorcio posea el mismo carácter? Nuevamente aparece frente a nosotros un doble estándar para el cual lo importante es que las personas ingresen a la institución conyugal, pero es preocupante que quieran concluirla.

Otro medio periodístico ${ }^{23}$ recordó lo que dijo la asociación Jueces para la democracia: "nos encontraremos a una Justicia a dos velocidades: una rápida para quienes puedan pagársela y otra cada vez más lenta para la mayoría de la sociedad".

Insistimos con preguntas que nos inquietan: ¿la labor judicial está condenada indefectiblemente a ser "más lenta"? ¿No deberían reclamar entonces por la agilización de los procesos judiciales? ¿Es un problema para la ciudadanía tener más opciones, o el problema es la pérdida de la exclusividad en esta competencia? ¿Por qué le preocupa tanto a esta asociación compartir los trámites de divorcio consensual cuando -según afirman- representan un número tan ínfımo frente a las labores judiciales?

Atento a que, en no pocas ocasiones, las críticas provienen de los medios de comunicación -reiteramos, no son impugnaciones jurídicas pero tienen su peso, desde el punto de vista social y cultural-, corresponde individualizar los pilares en que se apoyan. De este modo, y con independencia de los intereses que defienden, podemos extraer y sintetizar los fundamentos de la supuesta privatización. 
- Los escribanos públicos no son funcionarios públicos.

- Menores garantías para los ciudadanos.

- La ciudadanía debería abonar un servicio que, en sede judicial es gratuito.

\subsubsection{El carácter de funcionario público del escribano}

En el supuesto de la implementación del divorcio en sede notarial, consideramos que, a poco que se vea, el escribano es un fedatario público. Los temores de la mentada privatización carecen de sustento pues, en rigor, no existe estrictamente una transferencia de competencias al sector privado. No desconocemos que según el sistema al que cada país se halle adscrito, el escribano o notario puede, o no, ser un funcionario público. En cualquiera de los casos, la función misma que desempeña es siempre pública, aunque la ejerza un profesional independiente.

En el sistema de notariado latino, el escribano desempeña una función pública, pero no depende directamente de autoridad administrativa, aunque algunas de sus intervenciones son las de un funcionario público. A fortiori, es el Estado quien inviste al profesional como escribano público con el cargo de titular o adscrito de un registro notarial. Por añadidura, nótese que no existen los escribanos privados.

\subsubsection{Menores garantías para los ciudadanos}

Las asociaciones que nuclean a los magistrados y funcionarios ibéricos denuncian que, de aprobarse el anteproyecto de ley, habrá menos garantías para los ciudadanos, ${ }^{24}$ aunque no especifican en qué consistiría tal merma.

Esta denuncia no resulta novedosa, otros países ya la han atravesado con éxito. Es sabido que el temor a compartir competencias o, peor aún, a perderlas en favor de otro colectivo profesional (en el caso de la sede notarial); o de otro poder del Estado (sede administrativa), no sería atendido si se expusiera explícitamente. Por ello, la defensa suele esconderse bajo el velo de estos argumentos jurídicos. De este modo, se afirma - sin la más mínima intención de probarlo- que la desjudicialización provocaría una afectación a la legalidad, el derecho de defensa y el debido proceso.

\footnotetext{
${ }^{24}$ En el Anteproyecto de ley de Jurisdicción voluntaria se afirma: "Estos profesionales [los escribanos], que aúnan la condición de juristas y de titulares de la fe pública, reúnen sobrada capacidad para actuar, con plena efectividad y sin merma de garantías, en algunos de los actos de jurisdicción voluntaria que hasta ahora se encomendaban a los jueces".
} 
Esta impugnación se analizó en México. Allí, en sede administrativa, se objetó el divorcio que implementaron algunas entidades federativas, a través de juicios de amparo en los cuales se reclamaba su inconstitucionalidad. Se arguyó que violentaba las garantías de legalidad, debido proceso y de protección de la familia, entre otras. La Suprema Corte de Justicia de México resolvió que el divorcio consensual extrajudicial era constitucional, por no transgredir garantía ni derecho alguno. ${ }^{25}$

Justamente, frente a los reclamos en torno a su constitucionalidad, la Sala I de la Suprema Corte de Justicia resolvió que las reformas no vulneran la garantía de audiencia ni los principios de debido proceso.

Otros autores consideran que el cambio de sede constituye un obstáculo en el acceso a la justicia. Aunque resulte obvio, lo que estas voces pretenden es el acceso al Poder Judicial, no a la justicia, entendida como el valor que debe guiar el accionar no sólo de aquél, sino de todos los poderes y organismos del Estado.

No desconocemos que el derecho a la tutela judicial efectiva es un derecho constitucional. Es cierto, la ciudadanía requiere que la justicia sea efectiva.

Pero, aquí no existe conflicto. Las partes, mediante el mutuo consentimiento, solicitan legalizar su ruptura afectiva. ¿Acaso no podrían cumplir con esta tarea un oficial público del Registro Civil o un escribano público? Otra de las acepciones del vocablo justicia es derecho, razón, equidad. ¿El notario o el funcionario público no actúan con base en el derecho vigente, la razón o la equidad?

\subsubsection{La onerosidad o gratuidad del servicio}

En cuanto a la gratuidad de un servicio que, de trasladarse a una sede extrajudicial, debería abonarse, corresponde realizar un análisis diferencial. El principio general indica que toda actuación judicial debe tributar tasa de justicia, salvo exención expresa contenida en la ley. En Argentina, la Ley 23.898

\footnotetext{
${ }^{25}$ La primera Sala de la Suprema Corte de Justicia de la Nación (ScJN) resolvió, por mayoría de votos, el amparo directo en revisión 1819/2014, a propuesta de la Ministra Olga Sánchez Cordero de García Villegas. Al resolverlo revocó la sentencia recurrida y negó el amparo a un señor que impugnó su disolución del vínculo matrimonial, toda vez que, contrario a lo expuesto por el tribunal colegiado, el divorcio incausado, contenido en el artículo 582 del Código Procesal Civil para el Estado de Coahuila de Zaragoza, no es violatorio del párrafo cuarto del artículo 130 constitucional. Asimismo, sostuvo que el divorcio incausado no es violatorio ni del artículo 14, ni de la garantía de justicia imparcial contenida en el artículo 17, ambos constitucionales. Tampoco privilegia el derecho de la parte actora sobre el de la niñez, por lo que no es violatorio del artículo $4^{\circ}$ constitucional. Además, el artículo 585 del mismo código, al no admitir que la resolución de divorcio sea recurrida, tampoco vulnera derecho fundamental alguno, pues se privilegia la voluntad de quien no desea seguir en matrimonio. Véase Comunicado de prensa n 185/2014 de la Suprema Corte de Justicia de la Nación, México D.F., 23/10/2014, "El divorcio incausado, contenido en el artículo 582 del Código Procesal Civil para Coahuila no es violatorio del párrafo cuarto del artículo 130 Constitucional, resuelve Primera Sala", disponible en: http://www2.scjn.gob.mx/red2/comunicados/noticia. asp?id=2957
} 
prevé que estarán exentas del pago de la tasa de justicia "las actuaciones derivadas de las relaciones de familia que no tengan carácter patrimonial, las demandas por alimentos y litisexpensas, y las atinentes al estado y capacidad de las personas". Ello implica que el divorcio en sí mismo no debe tributar tasa de justicia.

Ahora bien, la sede administrativa resultaría igualmente gratuita. La regulación del Registro Civil se inspira en el principio de gratuidad que es la regla general en la materia, atento al interés público en torno a la concordancia entre lo registrado y la realidad.

Distinta es la situación en la sede notarial; pues, aquí sí, los honorarios notariales deberían ser solventados por los cónyuges y no por el Estado. El costo real de la sustanciación de un divorcio consensual en sede notarial es una cuestión de política legislativa que varía de acuerdo con la realidad socioeconómica de cada país. Es cierto que será más onerosa que la vía judicial, pero la diferencia no es de la magnitud que parece.

Muchos de los costos que tendría el procedimiento notarial deberían igualmente ser afrontados por los cónyuges que recurran a la vía judicial, llanamente, porque se refieren a los bienes que, como consecuencia de la disolución y liquidación del régimen de comunidad, deberán inscribirse en su nuevo carácter o titularidad. En ese sentido, la sede notarial sería económicamente similar a la vía judicial en lo que a tasas, tributos y sellados se refiere. En síntesis, a mayor caudal patrimonial, mayores son los estipendios, por tanto, en cuanto a la distribución de los bienes, no existe una mayor onerosidad.

Distinta es la situación en torno al honorario del escribano. Desde luego, no será gratuita su intervención, pues en ello va su ciencia, conocimiento y dedicación profesional.

Incluso, podría el arancel ser fijado por el Estado (verbigracia, el proyecto de ley de Jurisdicción voluntaria español prevé -en lo que aquí interesa- que el trámite tendrá un coste de 95 euros). ${ }^{26}$ Podrá discutirse si el arancel es más o menos justo y equitativo de acuerdo con la realidad socioeconómica de cada país. Lo que está fuera de discusión es que esta opción sólo podría ser utilizada por aquellas personas que puedan afrontar un costo económico, el cual, con la intervención judicial, asume el Estado.

\footnotetext{
${ }^{26}$ El gobierno autorizará matrimonios y divorcios ante notario a través de una reforma del Código Civil que incluirá la futura Ley de Jurisdicción Voluntaria, fijando un arancel de 95 euros por enlace, si bien, en el último caso estará sujeto a que no existan menores y se produzca de mutuo acuerdo entre la pareja. El Ministro de Justicia, Alberto Ruiz-Gallardón sostuvo "hay una nueva oferta de servicios y había que fijar el arancel, que el gobierno prevé fijar en 95 euros por cada matrimonio. Es una cantidad asumible dentro del coste general de celebración de una boda y no es un negocio juridico que se practique con mucha frecuencia". Diario La Ley, nº 8184, Sección Hoy es Noticia, 5/11/2013.
} 
Esta circunstancia no inhabilita la intervención del escribano, pues la sede notarial se regularía en forma facultativa, ${ }^{27}$ es decir, los cónyuges podrían optar -según sus posibilidades económicas- por recurrir a la vía judicial o a la extrajudicial.

Si bien ello constituye una cuestión de política legislativa, nos permite realizar algunas consideraciones en torno a la concurrencia o alternatividad en la competencia.

\subsubsection{Concurrencia o alternatividad de la competencia}

La atribución de competencias en torno al trámite de divorcio a otros operadores jurídicos no jurisdiccionales admite dos vertientes de contemplación, pues la atribución se puede hacer de manera no excluyente o de forma excluyente; aunque la tendencia ha sido la de compatibilizar las vías judicial y extrajudicial. A excepción de Cuba, ningún ordenamiento ha despojado al Poder Judicial de la competencia para conocer el divorcio por mutuo acuerdo.

En principio, el carácter excluyente de la atribución de competencia a los notarios u oficiales públicos del Registro Civil se presenta como un aspecto positivo, pues sería una muestra de un esfuerzo de especialización y organización racional que sirve para trasladar al ciudadano claridad sobre quién es el órgano competente en cada caso.

Así, el anteproyecto de ley español ${ }^{28}$ señala:

la distribución de los asuntos entre estos profesionales se ha realizado siguiendo criterios de racionalidad [...]. Para el mejor cumplimiento de esos fines, la Ley de Jurisdicción Voluntaria, a diferencia de algunos intentos anteriores de regulación, trata de evitar en la medida de lo posible la alternatividad entre los juzgados y otros operadores jurídicos, es decir, la posibilidad de acudir indistintamente a diferentes operadores para la obtención de un mismo efecto jurídico. Con ello se conjura la producción de duplicidades indeseables, contribuyéndose también a la clarificación de las funciones de cada uno y, con ello, a la seguridad jurídica, también exigible y relevante en este tipo de negocios jurídicos.

\footnotetext{
${ }^{27}$ En Brasil, el artículo $2^{\circ}$ de la Resolución nº 35 del 24 de abril del 2007 del Consejo Nacional de Justicia dispone que: "É facultada aos interesados a opção pela via judicial ou extrajudicial; podendo ser solicita, a qualquer momento, a suspensão, pelo prazo de 30 dias, ou a desistência da via judicial, para promoção da via extrajudicial".

${ }^{28}$ Exposición de motivos del Anteproyecto de Ley de Jurisdicción Voluntaria (apartado vi).
} 
Por el contrario, a favor de la variable no excluyente se explica que la concreción legal del objetivo de sistematizar y redistribuir competencias entre los diferentes profesionales jurídicos se traduce, entre otras cosas "en una mayor garantía para los ciudadanos al ampliar su ámbito de decisión a la hora de poder elegir en algunos casos quién va a llevar la actuación de que se trate [...]. Una libertad de opción que le permitirá tener en cuenta el coste de una opción u otra a la hora de decidir". El análisis es divergente cuando distinguimos ambas vías extrajudiciales. Cuando nos referimos a la sede notarial, la atribución no excluyente de competencias aparece como la opción más adecuada. Así, en el Informe del cGP ${ }^{29}$ se dice:

en nuestra opinión, podría ponderarse la posibilidad de recuperar el modelo de alternatividad que inspiraba el Proyecto de LJV 2006, de tal forma que en todos los asuntos encomendados a notarios y registradores pudieran también asumir competencias los secretarios judiciales. Esta fórmula permitiría así que el justiciable acuda a un secretario judicial al valorar la gratuidad de la justicia [...], o por el contrario, podrá optar en los supuestos contemplados legalmente, acudir a los servicios de un notario o un Registro Público, considerando que el pago del arancel fijado por el gobierno por vía reglamentaria, le compensará en la valoración sobre celeridad, proximidad o especialidad que realice.

En síntesis, mantener el carácter opcional entre la competencia de los órganos judiciales y la de otros órganos públicos no judiciales permite al ciudadano escoger entre una fórmula sufragada por el erario y otra cargada al patrimonio del promotor del expediente. De este modo, consideramos que, de optarse por la sede notarial, debería ser facultativa y, así, los cónyuges podrán elegir de acuerdo con sus posibilidades económicas.

Por el contrario, creemos que si la regulación prevé la instauración de una sede administrativa, debería ser excluyente para los divorcios consensuales; pues los argumentos esgrimidos con relación a la onerosidad del trámite resultan abstractos frente a una vía extrajudicial que permita su gratuidad.

A nuestro juicio, debería hablarse de una desjudicialización parcial, pues no implica que los jueces vayan a ser privados de toda competencia en materia de divorcio, sino que sólo se extraerán de su conocimiento aquellos casos donde, aun existiendo hijos y bienes comunes, los cónyuges brinden el mutuo

\footnotetext{
${ }^{29}$ Léase Consejo General del Poder Judicial de España.
} 
consentimiento para concluir su vínculo marital. En otras palabras, la labor de la judicatura quedaría circunscripta -en lo que aquí interesa- a los divorcios por petición unilateral.

\subsection{Que el divorcio ya es veloz}

En general, prestigiosos autores han manifestado algunos inconvenientes en torno a la viabilidad de la desjudicialización parcial en la Argentina, a la luz del nuevo Código Civil y Comercial de la Nación. El artículo 437 del nuevo ordenamiento regula el divorcio en sede judicial, limitando su trámite a la presentación de las propuestas reguladoras y la concurrencia a una audiencia o el convenio regulador. De allí, algunas voces afirman que este proceso ya es lo suficientemente veloz.

No basta que el proceso sea veloz. Resulta más importante que sea accesible, efectivo y alejado de los lugares que representan el litigio. Justamente, recurrir a la sede tribunalicia para regularizar una situación. De hecho, cuando la comunidad de vida, por distintas razones, ha cesado, choca con la lógica del divorcio sin expresión de causa, pues adolece del sentido práctico que éste conlleva.

El cambio de sede no implica necesariamente una mayor velocidad. El propósito no es darle una "mayor ligereza" al trámite del divorcio. La desjudicialización no supone, en modo alguno, una trivialización del matrimonio o la familia. Probablemente la rapidez del trámite sea similar pero, a nuestro juicio, el alejamiento de los tribunales se impone cuando no existe litigio.

Consideramos necesario evitar que los interesados tengan que recurrir al juez para darle un marco legal a la ruptura conyugal cuando no existe litigio alguno que dirimir. Ello es, en sí mismo, beneficioso, si logramos separar el divorcio de las cuestiones conexas. Nótese que si se cumplen los requisitos, el juez no tiene margen de acción más que para decretar el divorcio y homologar la autocomposición de las partes. Sólo frente a las discrepancias en los efectos, emerge su rol conciliador, pero ese no es el supuesto que nos ocupa.

La obligación de tener que recurrir a los tribunales para legalizar el quiebre conyugal desgasta necesariamente cualquier relación previa, pueden incluso aparecer conflictos donde no los había. Por el contrario, evitar la sede tribunalicia ayuda a conservar una relación de continuidad entre las partes. La génesis misma del judicante como un tercero superior, que debe resolver los problemas de los cónyuges, ocasiona que éstos se encuentren a sí mismos enfrentados, en una posición antagónica que quizás no existía anteriormente.

El divorcio sin expresión de causa posee una lógica interna que hace primar no tanto su "velocidad" sino su efectividad. A esta altura del análisis, 
corresponde realizar una precisión terminológica. Algo es eficaz si logra producir efectos o modificaciones en aras de un interés o meta propuesta; pero será efectivo si es observado y aplicado por sus destinatarios.

La judicialización choca contra la efectividad, pues las partes son más propensas a cumplir lo que por sí mismas convinieron, que lo resuelto por un tercero superior e imparcial.

El objetivo de gestionar los conflictos a través del consenso se merece, al menos, un esfuerzo y un ápice de confianza. El conflicto no es malo en sí mismo; lo negativo, en muchas ocasiones, es la forma en que se pretende resolverlo. Una ley no puede ni va a cambiar la personalidad más o menos conflictiva de los cónyuges, pero el efecto docente de la ley conlleva una tendencia a cerrarle caminos al conflicto.

\section{Objeciones jurídicas a la desjudicialización}

Ambas sedes extrajudiciales poseen un abanico de posibles regulaciones. Todas han recibido más o menos críticas que aquí intentaremos refutar, en el entendimiento de que la mayoría son sólo mitos arraigados en el imaginario. Analizaremos sintéticamente sólo aquellas que ofrecen mayor resistencia.

\subsection{Su viabilidad para los matrimonios con hijos}

El más delicado de los temas que suscita el divorcio extrajudicial concierne a su viabilidad frente a la existencia de hijos menores de edad, incapacitados o dependientes. Así, suelen adoptarse dos soluciones alternativas:

- La primera es regular el procedimiento extrajudicial para un universo de matrimonios que no posea hijos menores de edad o incapaces. Esta es la solución adoptada en Perú, Ecuador, Brasil y México [en sede administrativa]. En caso contrario, esto es, ante la existencia de hijos, los esposos sólo pueden acceder al divorcio en sede judicial.

- La postura opuesta consiste en admitir el divorcio extrajudicial en los supuestos de matrimonios con hijos menores de edad o incapaces y asegurar la protección de sus derechos mediante la intervención del Ministerio Público. Ello ocurre en Cuba, Colombia y Portugal, donde se requiere el dictamen o concepto del Ministerio Fiscal, defensor de familia o Ministerio Público, respectivamente. Su opinión será vinculante para la autoridad (notarial o administrativa) encargada de legalizar la ruptura conyugal. 
Los esposos deberán adecuar los acuerdos de conformidad a la opinión del funcionario; en caso de dictamen desfavorable con objeciones a lo convenido y que los cónyuges se nieguen a modificar sus pactos, se los tendrá por desistidos de su petición de divorcio.

Una tesitura intermedia o ecléctica es aquella que permite la sustanciación del divorcio consensual en sede extrajudicial, incluso a las parejas que posean hijos menores de edad o incapaces, pero que exige la intervención previa de los tribunales.

Esta posibilidad se encontraba en la normativa original de Portugal, donde si bien la existencia de aquellos no impedía el acceso a la sede administrativa, exigía que todas las cuestiones inherentes a los hijos debían ser previamente resueltas en sede judicial. Ello constituía una conditio sine que non para que el conservador del Registro Civil pudiera declarar disuelto el vínculo. La Ley 61/2008, del 31 de octubre de ese año, modificó la normativa primigenia y adoptó finalmente la solución colombiana.

Esta postura intermedia que promovía una doble intervención estatal y que fuera abandonada por la legislación lusitana no merece mayor análisis. Creemos que es necesario realizar algunos comentarios sobre la corriente mayoritaria que permite la vía extrajudicial sólo cuando no hay hijos menores de edad o incapaces.

Si bien intervienen factores metajurídicos, especialmente políticos, no observamos argumentos de índole jurídica para la desjudicialización del divorcio en matrimonios sin hijos. Actualmente, las discrepancias en el derecho comparado se circunscriben a la hipótesis de parejas que posean hijos. Pero corresponde hacer algunas aclaraciones.

Si excluyéramos este universo de parejas de la sede extrajudicial, no promoveríamos la consecución de algunos fines que se pretenden al instaurarla, esto es, la celeridad del trámite y la descongestión judicial.

Estamos convencidos de que la introducción del divorcio extrajudicial debe estar acompañada de una protección especial en favor de los hijos menores de edad o incapaces. ${ }^{30}$ La intervención del defensor de menores evita que, de lo propuesto en el convenio regulador, pueda derivarse un perjuicio para aquellos. Se logra en sede extrajudicial, lo cual a la postre se obtendría en sede judicial, luego de un agotador proceso.

Pero negarles la opción a los cónyuges ¿es una protección efectiva para los hijos? ¿Acaso impedirles a los progenitores un divorcio, que decidieron en

\footnotetext{
${ }^{30}$ En Cuba, interviene a fin de dictaminar el Ministerio Público Fiscal; en Rumania, resultan vinculantes los informes de los trabajadores sociales; y en Colombia, se ha atribuido esta función al defensor de familia, que es un funcionario administrativo, no judicial.
} 
común acuerdo, y confinarlos a los tribunales contribuye al interés superior del niño? Creemos que las respuestas negativas se imponen. Por el contrario, consideramos que la inclusión del Ministerio Público en el procedimiento extrajudicial luce acertada e ineludible.

\subsection{Asesoramiento letrado ¿forzoso o voluntario?}

Este es otro de los conflictos suscitados por los proyectos que promueven la desjudicialización del divorcio consensual: ¿la intervención letrada subsiste en la vía extrajudicial? A nuestro juicio, la respuesta positiva se impone, aunque no estrictamente por motivos jurídicos. En ese sentido, Cerdeira Bravo de Mansilla apuntó:

si nos atenemos a razones estrictamente jurídicas, no parece haberlas para defender como necesaria la intervención del abogado: ¿acaso ha de serla en el acto de celebración del matrimonio? ¿Por qué ha de serla, entonces, en su contrarius actus: el divorcio consensual? Ni siquiera pueden alegarse a favor de la intervención de letrado posibles motivaciones asesoras en cuestiones jurídicas más técnicas; ¿o acaso es preceptiva la intervención de abogado en la elaboración de capitulaciones matrimoniales? Para ello bastará con la intervención notarial. ¿Por qué no así también en el caso de un convenio regulador consensuado [incluso por el solo e imparcial notario]? Ha sido, no en vano, esa razón más política, de presión política a veces [dada la fuerza de los Colegios de Abogados], la que ha motivado prácticamente en todos los sistemas divorcistas extrajudiciales la imposición, como preceptiva, de la intervención de abogado [e incluso de procurador] en los divorcios consensuales [con la salvedad de Cuba]. Y ha sido aquella misma la razón, entre otras, que ha provocado entre nosotros el aborto de los diversos intentos de legislar con alcance general la jurisdicción voluntaria, por prescindirse en todos esos proyectos de la intervención de letrado como obligatoria. ${ }^{31}$

Las objeciones varían cuando nos referimos a la sede administrativa. Inclusive el citado autor reconoce que la intervención letrada sí sería necesaria frente al oficial público del Registro Civil, no así frente al escribano.

\footnotetext{
${ }^{31}$ Cerdeira Bravo De Mansilla, Guillermo. "Matrimonio no formalizado y divorcio notarial en Cuba: una propuesta de futuro para España", en Revista de Derecho Privado, 2011, p. 15.
} 
Huelga señalar que la preceptividad de la asistencia letrada y de la postulación técnica constituyen sendas opciones de política legislativa, perfectamente defendibles. Se pueden dar razones tanto para abogar por una mayor informalidad en el trámite del divorcio, como para defender la importancia de que la intervención en estos expedientes deba llevar el sello de calidad técnica de un profesional.

El Consejo General del Poder Judicial de España ${ }^{32}$ consideró que debería mantenerse la preceptividad. Recomendó la intervención del abogado en los procedimientos a desarrollar ante notario, "en particular los expedientes notariales de separación y divorcio, en los que incluso sería conveniente que cada parte actuara asistida de su propio letrado".

La participación del abogado pervive al cambio de sede; lo que cambia es su rol, al pasar de un papel confrontativo a otro conciliador. Su intervención cobrará otro matiz y precisará de un lógico acomodamiento en el modo de entender su función. En el divorcio inculpatorio en sede judicial, se requería que el abogado coadyuve a demostrar inconductas de los cónyuges y controvertir las causas del conflicto, en un proceso que servía para la denigración mutua y para que los esposos quedaran cada vez más ubicados en posiciones antagónicas.

Actualmente, el esfuerzo debe orientarse a la solución del problema de las partes, recordando que al interés del cliente se superpone el interés del grupo familiar. No debe olvidarse que el abogado está contribuyendo a crear un nuevo sistema de vida, ni mejor ni peor, simplemente diferente.

\subsubsection{Doble asesoramiento profesional}

Ahora bien, si consideramos que la intervención letrada subsiste, se direcciona el análisis a otro de los tópicos que generan las impugnaciones más recurrentes frente a la desjudicialización parcial del divorcio y se agudizan cuando se elige la sede notarial.

Desde la abogacía se observa con recelo la atribución a los notarios de estos procedimientos. Así, el colectivo profesional potencialmente afectado (abogados) teme que la hipotética regulación lo excluya del trámite extrajudicial. Cuando la vía elegida es la notarial, el colectivo beneficiado (escribanos) considera que el asesoramiento legal bien podría ser brindado a los cónyuges por un escribano. ${ }^{33}$

La controversia podemos sintetizarla en una potencial duplicidad o superposición de funciones entre el escribano y el abogado; un doble asesoramiento

\footnotetext{
${ }^{32}$ cGPJ de España, Informe al Anteproyecto de Ley de Jurisdicción Voluntaria 2014, punto 120.

${ }^{33}$ Ocurre que los notarios tienen la función de asesorar a quienes solicitan sus servicios y proporcionar información acerca del medio jurídico más adecuado para el logro de sus objetivos, como profesionales del derecho que son.
} 
profesional con el consecuente incremento de costos para los interesados. Si bien, no es un diferendo que pueda plantearse frente a la sede administrativa, sí es una cuestión sumamente debatida cuando se opta por la sede notarial. ${ }^{34}$

No se nos escapa la pugna de intereses entre ambos colectivos profesionales, pero pretendemos que los aportes académicos sirvan como insumos para un real beneficio a la ciudadanía y un paso más en la efectividad del ejercicio de sus derechos. Por ello, no podemos dejar de advertir que, a poco que se observe, la alegada superposición de funciones es un argumento más efectista que real.

Messía de la Cerda Ballesteros nos ayuda con su claridad a dilucidar el conflicto; pues si bien las funciones de ambos profesionales poseen cierta similitud, no se pueden equiparar. El abogado posee una función de defensa, no sólo asesora. En cambio, el notario no participa desde la posición de uno o ambos cónyuges, sino que ostenta una ubicación en el procedimiento equidistante.

El autor apunta:

el notario posee una naturaleza híbrida, que conjuga aspectos propios de un funcionario público, que lo es, con los de un profesional del derecho. En este sentido, es lógico que él mismo deba prestar servicios de resolución del divorcio y, a la vez, de asesoramiento técnico. Así, la participación del notario no debe afectar, ni mucho menos, a la posición de los abogados. La neutralidad del notario exige la intervención de otro profesional que defienda los intereses de parte. ${ }^{35}$

El factor decisivo es, entonces, la distinta naturaleza de los asesoramientos. El abogado presta un asesoramiento de parte, defiende los intereses de su cliente, por lo que su información está encaminada siempre a favorecer las pretensiones de aquel. En cambio, el notario debe adoptar una posición de neutralidad para llegar a los fines comunes y objetivos de ambas partes, pero sin que pueda bascular a favor de una u otra. Por ello, considera que ambos asesoramientos son compatibles. El escribano cumplirá un rol de asesoramiento e imparcialidad, mientras el abogado tendrá una función defensiva.

\footnotetext{
${ }^{34}$ Gomá Lanzón, IGnacio. "Notarios, matrimonios y jurisdicción voluntaria", en El Notario del siglo xXI, No. 42, Colegio Notarial de Madrid, 2012, p. 4.

Algunos autores recuerdan numerosos supuestos en los que los ciudadanos acuden al notario asistidos por un abogado. De alli el temor a que un incremento de los costes pueda reducir la intervención de los abogados y, con ello, sus honorarios; no parece -según su opinión- ajustarse a la realidad. En ese sentido, Gomá Lanzón sostuvo que es muy probable que, a los efectos de la remuneración notarial, se consideren tales actos como documentos sin cuantía. ${ }^{35}$ Messia de la Cerda Ballesteros, Jesús A. "La implantación del divorcio por mutuo acuerdo ante notario en España", en Revista Crítica de Derecho Inmobiliario, No. 734, Madrid, 2012, pp. 3389 y 3390.
} 


\section{La sede notarial}

La instrumentación de la vía notarial en países iberoamericanos no es casual, sino obedece a la conformación de la profesión notarial según los parámetros del notariado latino, pues las funciones del escribano latino superan, en demasía, las tareas de un mero legalizador de documentos; realiza además juicios de capacidad y legalidad.

En el ámbito iberoamericano existen distintas regulaciones que han atribuido la competencia al notario. Podemos mencionar los casos de Cuba, Colombia, Ecuador, Brasil, Perú, Bolivia y Nicaragua, donde el divorcio puede ser llevado a cabo ante notario público y la escritura pública reemplaza la sentencia. Todos los regímenes citados exigen que los cónyuges presenten un convenio regulador de todas las cuestiones derivadas del vínculo marital. Sin embargo, a excepción de Cuba y Colombia, las normativas requieren que no existan hijos menores de edad o incapaces.

Se ha dicho que el notario intervendría en el divorcio como creador del nuevo derecho preventivo, controlando la legalidad de los acuerdos, sin contradicciones, ni lesión de los intereses de los hijos menores, ni de uno de los cónyuges. De modo que la escritura pública de divorcio esté apta para el tráfico jurídico, garantizando la debida publicidad del acto, sin el costo personal y patrimonial que un largo y tortuoso proceso de divorcio en sede judicial causa a todos los implicados en él. ${ }^{36}$

Algunas de las impugnaciones analizadas con antelación se han planteado con mayor intensidad frente a la sede notarial, particularmente aquellas referidas a la falta de una real agilización económica y temporal. En ambos casos, remitimos en honor a la brevedad a lo expuesto ut supra. En relación con la falta de celeridad en el trámite, reiteramos: no resulta una impugnación válida, pues no es el objetivo buscado.

Messía de la Cerda Ballesteros ${ }^{37}$ afirmó:

no parece que la atribución a los notarios del divorcio por mutuo acuerdo fuera a suponer realmente un ahorro de costes temporales y económicos. En el caso español habría que analizar cómo se incardina tal actuación en el procedimiento notarial, a la vez que supondría una complicación de unos procedimientos como los notariales que se caracterizan por su rapidez y agilidad. Si bien se agilizarían los procesos judiciales, no se obtendría la agilidad propia de las notarías.

\footnotetext{
${ }^{36}$ Pérez Gallardo, Leonardo B., "El divorcio por mutuo acuerdo...", op. cit.

37 Messia de la Cerda Ballesteros, Jesús A. "La implantación del divorcio...", op. cit., p. 3355.
} 
Coincidimos con Pérez Gallardo, quien no comparte...

la opinión de aquellos juristas que han estudiado el tema de la atribución de competencias al notario en sede de divorcio por mutuo acuerdo desde un análisis pragmático del derecho, sobre la base de costes económicos y descongestión de los tribunales. Ahí no está la esencia de esta medida. No se trata de disminuir o aumentar costes económicos, tampoco de descongestionar la labor de los tribunales, aunque indirectamente ello repercuta en ambos sentidos. ${ }^{38}$

Si bien la desjudicialización parcial del divorcio posee esos efectos positivos, no son los propósitos buscados por una reforma legislativa.

Se busca adecuar el procedimiento a la nueva fisonomía del divorcio, a la luz de la doctrina internacional de los derechos humanos, pues el ejercicio de un derecho no implica necesariamente su judicialización. Justamente, la potenciación de la autonomía de la voluntad de los cónyuges no implica, en modo alguno, la privatización del divorcio.

Otra cuestión son los costos de la sede notarial, pues como adelantamos, no necesariamente producirá un abaratamiento en términos económicos. ${ }^{39}$

En síntesis, salvo algunos supuestos excepcionales, la sede notarial no pareciera mostrarnos una disminución económica, sino una paridad con la actual sede judicial, máxime si incluimos el necesario asesoramiento jurídico.

Sucede que la asunción por los notarios de la competencia supone un ahorro directo para el Estado de los costes judiciales y de la administración de justicia. Sin embargo, tal ahorro se conseguiría mediante el traspaso de dichos costes a la ciudadanía, la cual tendría que abonar los servicios recibidos de un profesional público, como es el notario. Se han propuesto medidas para minimizar el impacto económico que supondría para los ciudadanos. ${ }^{40}$ En opinión de Messía de la Cerda Ballesteros, "en la situación presente el divorcio ante notario podría suponer un incremento del coste para las parejas. A tal efecto, debemos recordar que las reformas propuestas no eliminan, en principio, la necesidad de intervención de abogado, por lo que parece que aumentaría la cuantía final, al permanecer invariados los costes del procedimiento judicial y añadir los propios de la notaría". ${ }^{11}$

\footnotetext{
38 Pérez Gallardo, Leonardo B. "Divorcio por mutuo consentimiento ante notario...", op. cit.

${ }^{39}$ A modo ilustrativo, en Colombia el notario cobra lo mismo que por una actuación sin cuantía; en Ecuador, se impone el arancel básico unificado (de 170 dólares); y en Brasil, podría ser gratuita el acta notarial sólo para quienes carecen de recursos.

${ }^{40}$ GOMÁ LANZÓN, IGNACIO. "Notarios, matrimonios y jurisdicción voluntaria", op. cit., p. 4.

${ }^{41}$ Messia De la Cerda Ballesteros, Jesús A. "La implantación del divorcio...", op. cit., p. 3353.
} 
Algunas preguntas quedan flotando en el aire: ¿se debe regular el pago de un arancel por la escritura pública de divorcio o los honorarios del escribano interviniente? El costo que demande la inscripción de la escritura en el Registro Civil, ¿se encuentra incluido en el arancel fijado o debe ser afrontado por los interesados?

Si bien muchas de estas preguntas son cuestiones de política legislativa, variantes de acuerdo con la idiosincrasia del país que promueva la regulación, todas ellas alimentan sensiblemente los costos económicos del acceso al notario.

Concatenado con ello, no podemos dejar de observar que si pretendemos una propuesta legislativa para todo el universo social de nuestro país, la accesibilidad a un escribano aparece prima facie más restringida en comparación con los registros civiles.

La cuestión de la accesibilidad representa una realidad en nuestro medio. No le debemos confundir con el mito del elitismo, esto es, que la sede notarial sería para pocos, relegando a la mayoría a la sede judicial, pues esta hipótesis es sólo eso: un mito. Reconocemos su carácter ficticio, igual que el de otras objeciones extrajurídicas con relación a la intervención del escribano, pero consideramos que su enquistamiento en el imaginario social, tamizado mediante décadas de consolidación cultural -especialmente dentro de los colectivos profesionales afectados-, resulta, de momento, insuperable en la Argentina.

\section{Colofón}

La desjudicialización contribuye a la rápida definición del estado civil de las personas, para que los verdaderos protagonistas concentren sus esfuerzos en acordar lo atinente a los derechos, deberes e intereses de todos los integrantes del grupo familiar.

En ambas sedes extrajudiciales podemos encontrar ventajas y desventajas $y$, por los argumentos expuestos, consideramos que resultan superadoras de la sede judicial.

A nuestro juicio, la regulación más acorde con la perspectiva interdisciplinaria y la obligada mirada constitucional-convencional que profundiza sobre las nociones de libertad, autonomía personal e injerencia estatal mínima, es aquella que promueve la desjudicialización parcial del divorcio y permite obtenerlo, en caso de mutuo acuerdo, en sede extrajudicial.

La vía notarial ha tenido un gran éxito en el ámbito latinoamericano, pero no se nos escapa que importar simplemente lo mejor de aquellos modelos ajenos a nuestra sociedad no es sinónimo de éxito. Por el contrario, aquellas 
normas foráneas bien pueden no adaptarse a la idiosincrasia de nuestra sociedad. Eso es precisamente lo que ocurre aquí.

La resistencia a la sede notarial que se esconde, por cierto, detrás de argumentos jurídicos (respecto de los cuales nadie podría estar en contra) y a la postre aflora entre los profesionales del derecho impide, de momento, su viabilidad.

No desconocemos que el argumento del doble asesoramiento o, en otras palabras, la supuesta colisión entre la labor del escribano y el abogado no es tal, e incluso ha sido rebatida por distintos autores. Sin embargo, este aporte interpela a nuestra sociedad, nuestras leyes y la necesaria adecuación de éstas a la primera. Vienen a la memoria las palabras de Raymond Aron, quien sostuvo que "en política no sirve tener razón antes de tiempo".

Todo ello nos conmina a prestar atención a factores extrajurídicos y a la potencial resistencia que tiene -en nuestro medio- la sede notarial.

Hemos dejado en último lugar una objeción, o pseudo-argumento que poco tiene de jurídico, con el cual algunas voces suelen denostar la desjudicialización propuesta: "nuestro país no está preparado para el cambio".

Sin perjuicio de advertir la subestimación que fácilmente puede observarse en esa mirada en torno a nuestra sociedad y la de aquellos países que ya han implementado otras sedes, a nuestro juicio, la sociedad argentina está preparada y madura para dar un paso más en este camino hacia un derecho matrimonial laico que sea útil a sus destinatarios, independientemente de si agrada a ciertos operadores jurídicos.

¿Acaso no estaba preparada para la sanción de la Ley 23.515, o la Ley 26.618 o incluso, más recientemente, el Código Civil y Comercial de la Nación? Desde aquí fogoneamos su discusión. 